\title{
Implementation of LAN (Local Area Network) Network on PT Aplikanusa Lintasarta
}

\author{
Septian Hadinur Ichsan \\ Informatics and Computer Engineering \\ State Polytechnic of Jakarta \\ J1. Prof. Dr. G.A Siwabessy, Kampus Baru UI, Depok 16424 \\ septian.ichsan.tik15@mhsw.pnj.ac.id
}

\begin{abstract}
PT Aplikanusa Lintasarta Project Management and Resource Management (PMRM) division has the task to providing network services and manage networks that are used both for PT Aplikanusa Lintasarta and clients. PMRM division has several problems, one of which is the replacement and addition of network devices used so that it must do a new network configuration. One of the solutions offered is to implement a Local Area Network (LAN) in PMRM division. This network implementation is needed because the network at the company will someday develop more along with the many users and technological developments. LAN implementation uses several network devices, like a router, switch, network cable (UTP cable), and PC or laptop as user. Some of features that used in this LAN network are website blocking, (Dynamic Host Configuration Protocol) DHCP, Hotspot, and bandwidth. Testing on LAN networks is done by calculating throughput, delay, and packet loss. This test is needed to find out how well LAN network works.
\end{abstract}

Keywords- Local Area Network, Dynamic Host Configuration Protocol, Hotspot, Bandwidth, Router, Switch

\section{INTRODUCTION}

The number of internet users worldwide in 2017 was 3.65 billion compared to the number of internet users in 2016 of 3.4 billion [1]. Internet users have increased due to technological and communication developments rapidly especially on computer networks. Computer networks are now widely used in various places, one of which is in company such as PT Aplikanusa Lintasarta. PT Aplikanusa Lintasarta is a data communication service provider company that has a head office in Jakarta and branch offices spread throughout almost Indonesia. One of the divisions related to the network at PT Aplikanusa Lintasarta is Project Management \& Resource Management division (PMRM).

Workspace of the PMRM division has around 20 employees, which consist of the main room, server room, manager's room, and meeting room. PMRM division has several problems, one of which is the replacement and addition of network devices used so that it must do a new network configuration. One solution offered for these conditions is to implement a Local Area Network (LAN) in the PMRM division. Implementation on Local Area Network (LAN) that carried out at PT Aplikanusa Lintasarta PMRM division is needed because the network at the company will someday develop along with the many users and technological developments. LAN Implementation at PT Aplikanusa Lintasarta PMRM division is also needed because new network device that used will increase performance and security on the network.

The features that will be used to implement this LAN network, such as Dynamic Host Configuration Protocol (DHCP) Server, Firewall, Hotspot, Bandwidth, and others
[2]. This journal focuses on the process of implementing LAN networks at PT Aplikanusa Lintasarta PMRM division. This is done by configuring the network devices that are used according to the features that will be used. One of network devices that used in the implementation of LAN networks is the HAP 952 Mikrotik router [3]. This router was chosen as a router used in PT Aplikanusa Lintasarta PMRM division because of various advantages, such as the wireles feature that allows users to connect to the network via hotspots, easy to use, and suitable for use on a small to medium scale.

\section{DETERMINING NETWORK TOPOLOGY}

Determining the network topology is done so that the network used in a place works more efficiently and more optimally based on the needs and network devices used by the place. Network topology is the arrangement or interconnection mapping between nodes, from a network, both physically (real) and logical (virtual) on a network [4].

The network topology used for Local Area Network (LAN) networks in PT Aplikanusa Lintasarta division Project Management and Resource Management is a tree topology. This topology was chosen because of several advantages as follow [5]:

- Identification of damage to the network can be done easily.

- Can be applied to computer networks with medium to large scale.

- If there is one user experiencing interference or damage, it does not affect other users.

- 4. Network development can be done easily.

Tree topology that will be used on LAN networks at PT Aplikanusa Lintasarta in the Project Management and Resource Management division consists of external networks (internet), Cisco routers (central routers), Mikrotik wireless routers, switches, and several user computers. Mikrotik wireless router is used so that users who cannot connect with a network cable (UTP cable) can connect to a LAN network. This can be seen in the following picture.

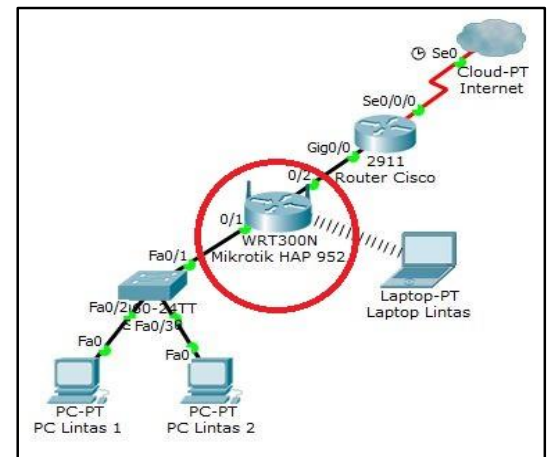

Fig 1. Network topology Local Area Network (LAN) PMRM division 


\section{WIRELESS CONFIGURATION}

Wireless configuration stage on the Mikrotik router is done after determining the network topology to be used. This is done so that users who are not connected to the LAN network can connect to the network via wireless (Via SSID). Wireless configuration can be done in Winbox software. Wireless interfaces must be activated first on the "wireless" menu in Winbox to enable wireless services on network [6].

Wireless configuration includes wireless mode and SSID which can be seen in the following figure.



Fig 2. Configuring wlan1 in Wireless Tables

\section{MIKROTIK CONFIGURATION AS INTERNET GATEWAY}

Mikrotik configuration as internet gateway aims so that users can connect with a Local Area Network (LAN) network that will be created and can be connected to the internet. Mikrotik configuration as internet gateway includes IP address, DNS server, DHCP server, routing, and Network Address Translation (NAT) configuration.

IP address configuration aims to provide an identity to the Mikrotik router according to the interface used which can be seen in the following figure.

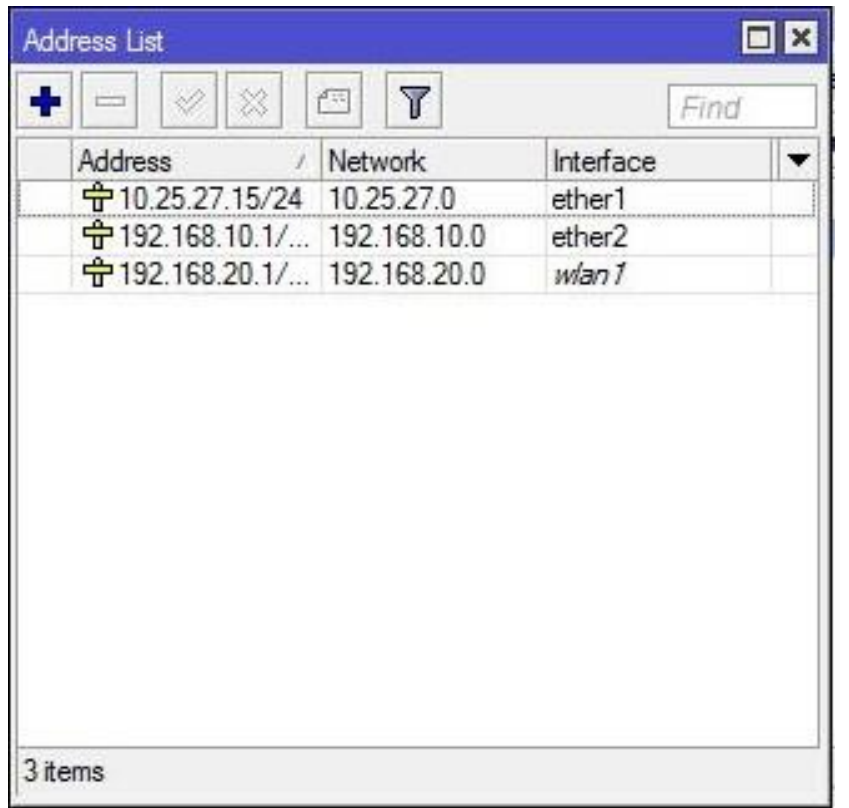

Fig 3. Configure the IP Address on Mikrotik router
DNS server configuration aims to translate domain names to IP addresses and IP addresses to domain names which can be seen in the following figure.



Fig 4. Configure the (Domain Name Server) DNS server on Mikrotik router

DHCP server configuration aims to aims to get the user to get an IP Address automatically which can be seen in the following figure.

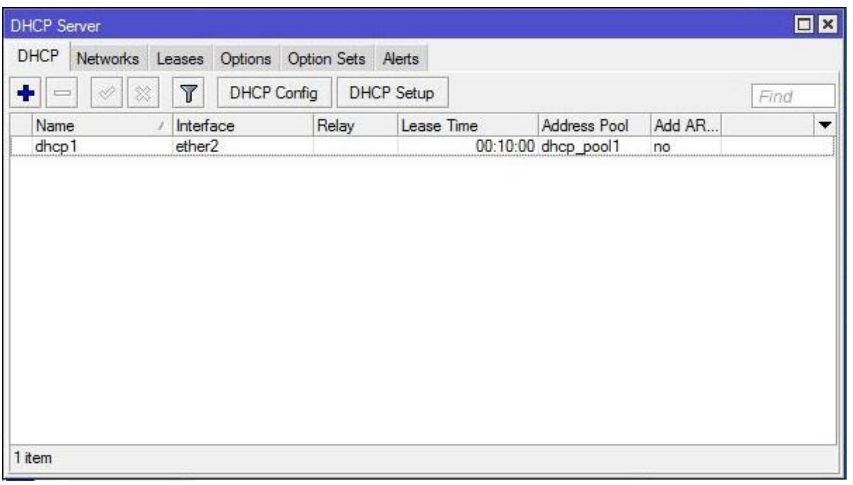

Fig 5. Configure the DHCP server on Mikrotik router

Routing configuration aims to so that the Mikrotik router can connect to the internet and connect to other LAN networks which can be seen in the following figure.



Fig 6. Configure the routing on Mikrotik router

Network Address Translation (NAT) configuration aims so that the Microric router can connect to the internet by adding rules in the "NAT" tab to the "Filter Rules" service which can be seen in the following figure. 


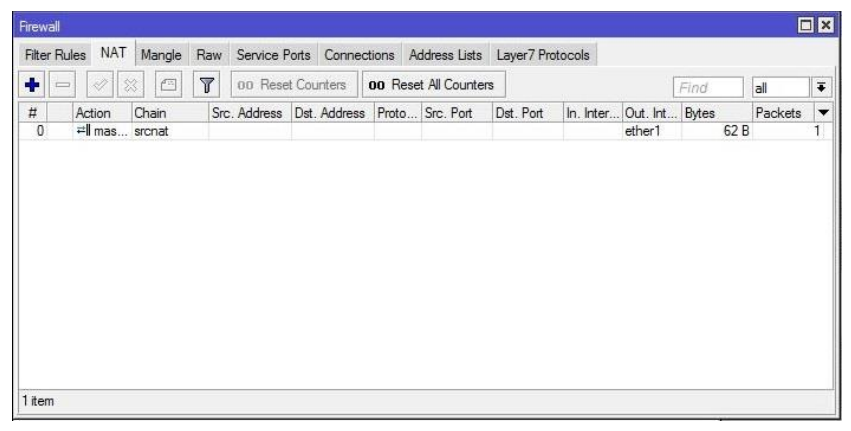

Fig 7. Configure the NAT on Mikrotik router

\section{HOTSPOT CONFIGURATION}

Hotspot configuration aims to allow users to connect to a Local Area Network (LAN) network through a hotspot network. Users of this hotspot network must authenticate in the form of logging in a hotspot site to be able to connect to the internet and LAN networks. Hotspot configuration includes hotspot setup and add users [7].

Hotspot setup is a hotspot service that is used for basic configuration in hotspots which includes configuration interfaces, IP hotspots, IP DNS hotspots, hotspot domain names, adding users, and others which can be seen in the following figure.

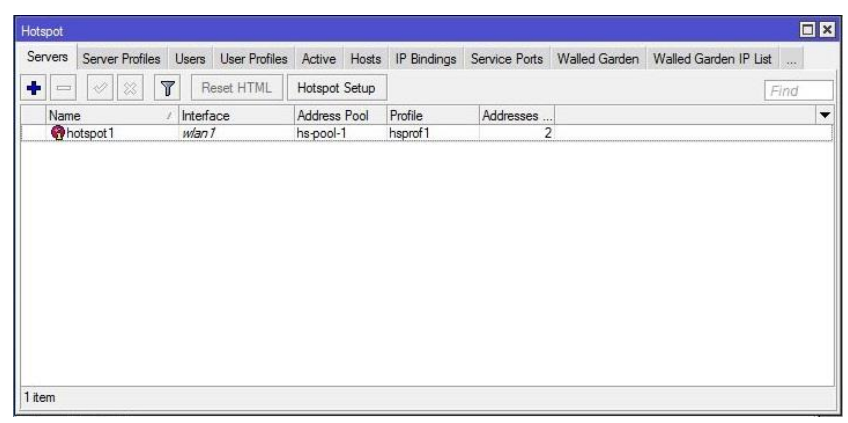

Fig 8. Configure the hotspot

Add user is a hotspot service that is used to add users who can use hotspot services through logging in via a hotspot website which can be seen in the following figure.

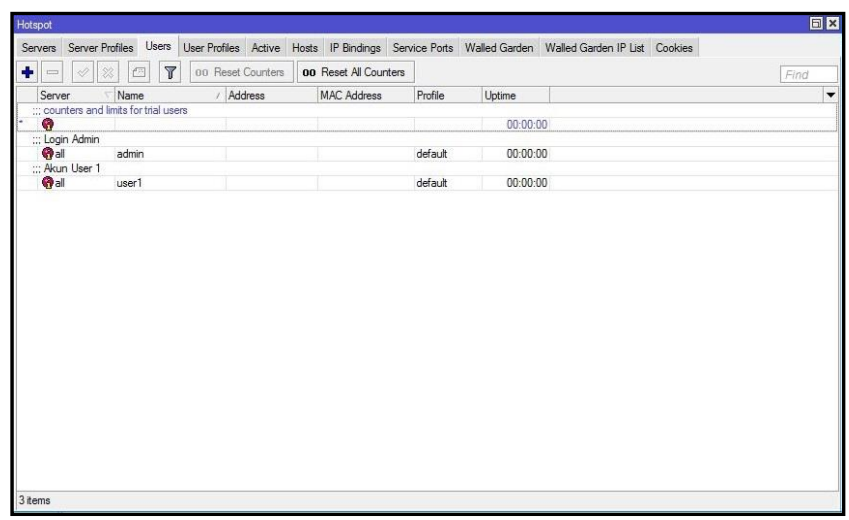

Fig 9. Account list used in hotspots

\section{WEBSITE BLOCK AND BANDWIDTH CONFIGURATION}

Website block configuration carried out at this stage to block certain sites, such as social media sites, pornographic sites, drug sites, and so on. The website block configuration uses the firewall feature on the Mikrotik router to manage which data packets are blocked according to the rules of the firewall [8]. Website block configuration includes web proxy, web proxy access, and NAT rules for web proxy.

Web proxy configuration aims to allow network users to access a service on the network to go through the port used on the Mikrotik router. Configuring a web proxy can be done in the IP menu on Winbox which can be seen in the following figure.

\begin{tabular}{|c|c|c|c|c|c|}
\hline \multicolumn{5}{|c|}{ Web Proxy Settings } & $\square \times$ \\
\hline General & Status Lookups & Inserts & Refreshes & & OK \\
\hline \multicolumn{5}{|c|}{$\checkmark$ Enabled } & Cancel \\
\hline \multicolumn{2}{|r|}{ Src. Address: } & \multicolumn{2}{|c|}{$\because:$} & \multirow{3}{*}{$\begin{array}{l}] \leqslant \\
\Rightarrow\end{array}$} & Apply \\
\hline \multirow{2}{*}{\multicolumn{2}{|c|}{ Port: }} & \multicolumn{2}{|c|}{3128} & & \\
\hline & & \multicolumn{2}{|c|}{$\square$ Anonymous } & & Clear Cache \\
\hline \multirow{3}{*}{\multicolumn{2}{|c|}{$\begin{array}{l}\text { Parent Proxy: } \\
\text { Parent Proxy Port: }\end{array}$}} & & & \multirow{3}{*}{$\nabla$} & \\
\hline & & & & & Access \\
\hline & & & & & Cache \\
\hline \multicolumn{2}{|c|}{ Cache Administrator: } & Nebmaster & & $\Delta$ & Direct \\
\hline & Max. Cache Size: & unlimited & $\mp$ & $\mathrm{KBB}$ & Connections \\
\hline \multirow{2}{*}{\multicolumn{2}{|c|}{ Max Cache Object Size: }} & 2048 & & \multirow[t]{2}{*}{$\mathrm{KB}$} & Cache Contents \\
\hline & & \multicolumn{2}{|c|}{$\checkmark$ Cache On Disk } & & \\
\hline \multicolumn{2}{|c|}{ Max. Client Connections: } & \multicolumn{3}{|c|}{600} & \\
\hline \multicolumn{2}{|c|}{ Max. Server Connections: } & \multicolumn{3}{|c|}{600} & \\
\hline \multirow{3}{*}{\multicolumn{2}{|c|}{ Max Fresh Time: }} & \multicolumn{3}{|c|}{ 3d 00:00:00 } & \\
\hline & & \multicolumn{3}{|c|}{$\square$ Serialize Connections } & \\
\hline & & \multicolumn{3}{|c|}{$\square$ Always From Cache } & \\
\hline \multicolumn{2}{|c|}{ Cache Hit DSCP (TOS): } & \multicolumn{3}{|c|}{4} & \\
\hline \multicolumn{6}{|l|}{ running } \\
\hline
\end{tabular}

Fig 10. Web proxy configuration

Web proxy access is needed to set rules that are applied to a service, such as a website in the web proxy access menu by adding a rule to a web proxy which can be seen in the following figure.



Fig 11 . Web proxy rule in web proxy access

NAT rules for web proxy aims so that users who access a service, such as a website, must pass a web proxy service. The web proxy service already contains a rule where users access the site on the rule by adding rule for web proxy in "Filter Rules" which can be seen in the following figure.

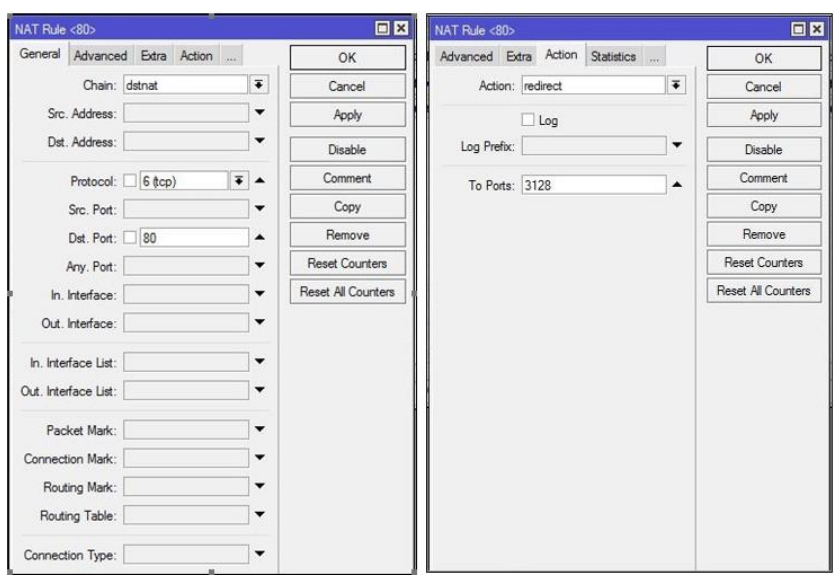

Fig 12. Configure NAT rules for web proxies

Bandwidth configuration on a network Local Area Network (LAN) is done to limit the speed of data transfer according to network users. Bandwidth configuration uses the queue feature to adjust the data transfer speed according to 
the rules made in the queue. Bandwidth configuration uses the queue feature and the simple queue method on the Mikrotik router [9]. Bandwidth configuration includes employee and guess bandwidth.

Employee bandwidth is given an upload and download speed limit of 5M (Megabit per second) and guess bandwidth is given an upload and download speed limit of $2 \mathrm{M}$ (Megabit per second) which can be seen in the following figure.

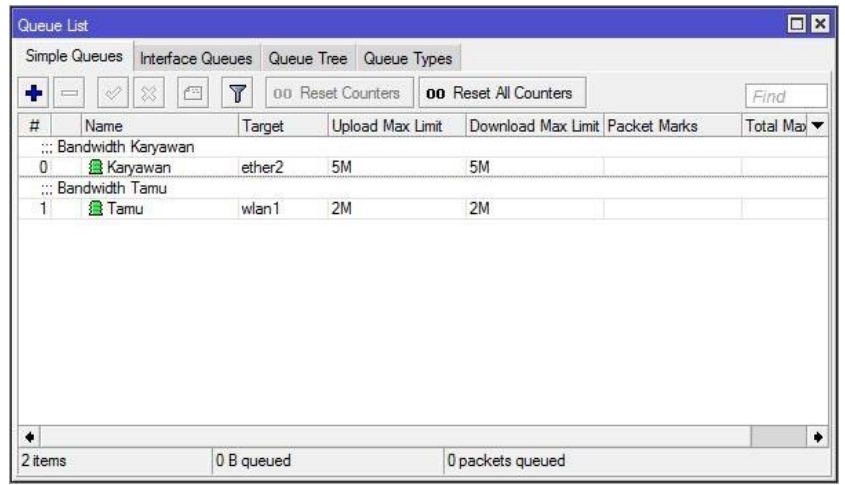

Fig 13. Bandwidth configuration for employees and guests

\section{TESTING}

Testing on a Local Area Network (LAN) network is needed to be able to prove the configuration that has been done and ensure that the LAN network can be used. Testing on a Local Area Network (LAN) network includes network connectivity, login at hotspot website, website block, bandwidth testing. Testing on a network Local Area Network (LAN) also includes Quality of Services (QoS) testing which consists of throughput, delay, and packet loss testing. Quality of Service (QoS) testing is needed to find out how well a network provides a service.

Network connectivity testing is done to find out whether the user can connect to the LAN network and access the internet which can be seen in the following figure.

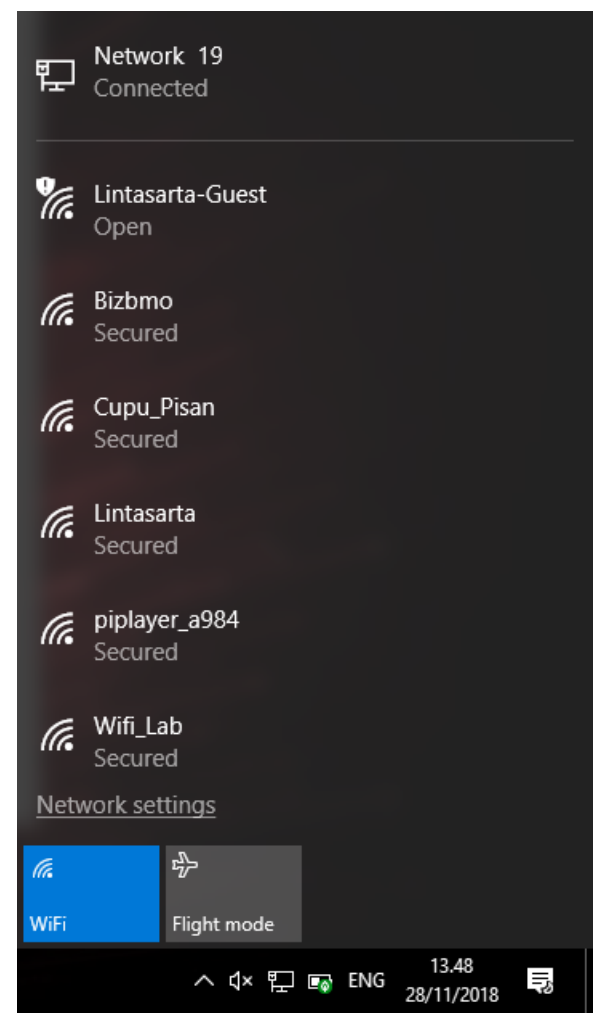

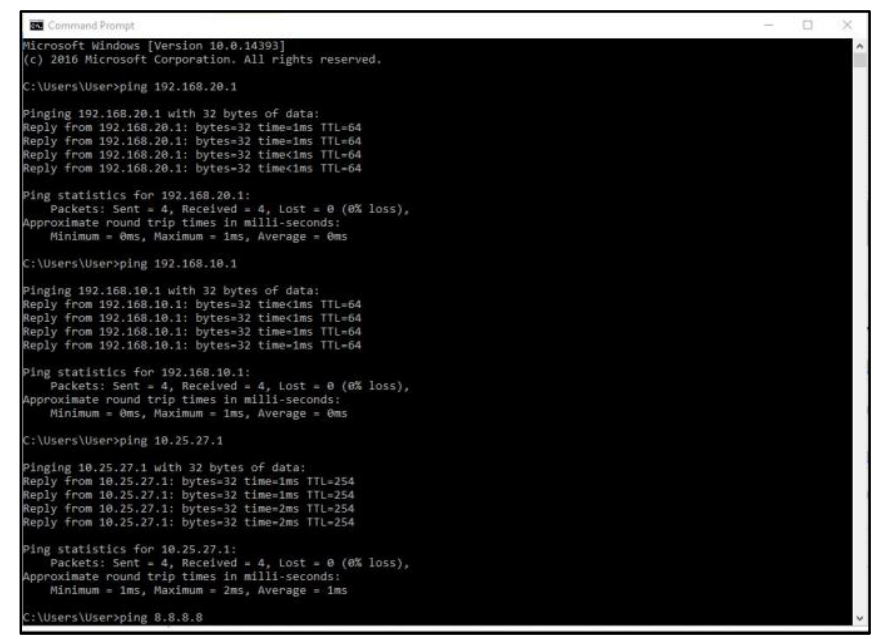

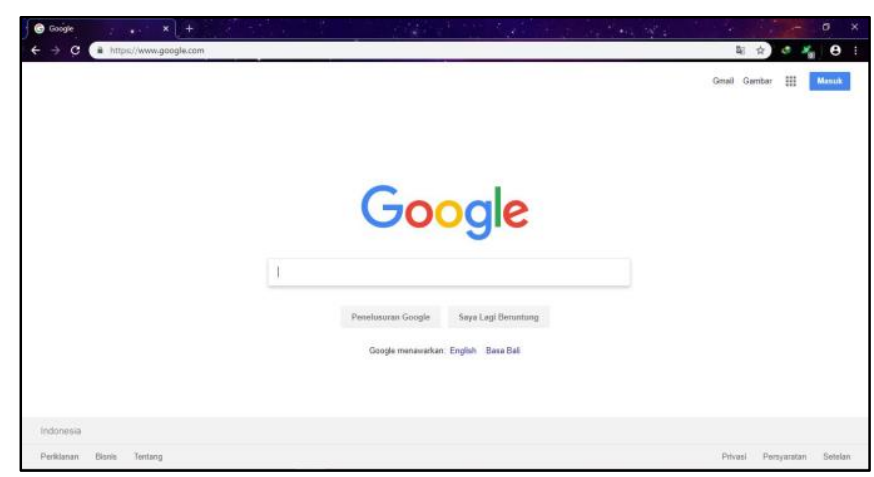

Fig 14. Network connectivity testing

Login at hotspot website testing is done by accessing any site on a web browser that will automatically be redirected to the hotspot login site. If successful, the hotspot login site with the hotspot.wifilintas.net address will appear. Testing is done using a hotspot account with an admin login and admin password which can be seen in the following figure.

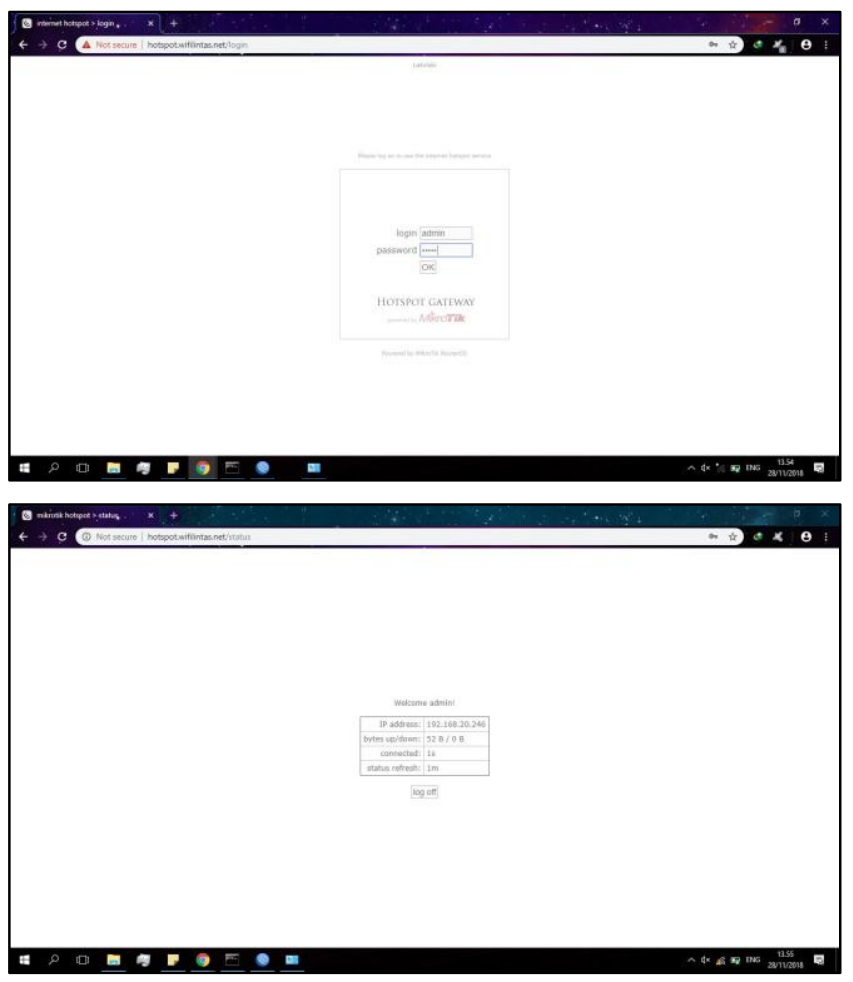

Fig 15. Login at hotspot website testing

Website block testing is done by accessing the site www.detik.com which has been blocked by using a web proxy service. If the www.detik.com site does not appear but the error: Forbidden appears as shown below, then the 
website block configuration has been successful which can be seen in the following figure.

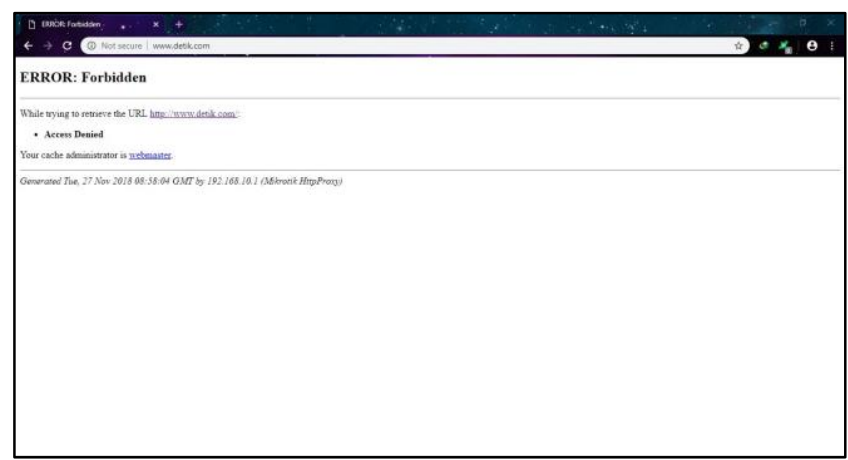

Fig 16. Website block testing testing

Bandwidth testing is done to determine the data transfer speed before it is restricted and after being limited by the queue service on the Mikrotik router.


Fig 17. Bandwidth testing

Throughput testing is needed to determine the average speed of data transfer. Throughput testing uses the Wireshark application by capturing packets on a LAN network. The capture results in the package can be seen in the Capture files properties sub menu on the Statictic menu as shown below. The throughput caught on LAN networks is in two versions, namely the average in units of bytes (Average bytes / s) and the average in bits (Average bits / s).

\begin{tabular}{|llll|}
\hline Statistics & & & \\
Measurement & Captured & Displaved & Marked \\
Packets & 4317 & - \\
Time span, $\mathrm{s}$ & 31.855 & $317(100.0 \%)$ & - \\
Average pps & 135.5 & 1355 & - \\
Average packet size, B & 1074 & 1075 & - \\
Bytes & 4634387 & $4634387(100.0 \%)$ & - \\
\hline Average bytes/s & $145 \mathrm{k}$ & $14 \mathrm{k}$ & - \\
Average bits/s & $1163 \mathrm{k}$ & $1163 \mathrm{k}$ & - \\
\hline \hline
\end{tabular}

Fig 18. Throughput testing

Delay testing is done to determine the delay time caused by the process of transmitting packets from one point to the destination. Delay testing uses the command prompt (CMD) with the ping command to www.google.com and the
Wireshark application by capturing packets on the LAN network. The package used in the purpose of this delay is the ICMP package with packet number 188 and package 212 .

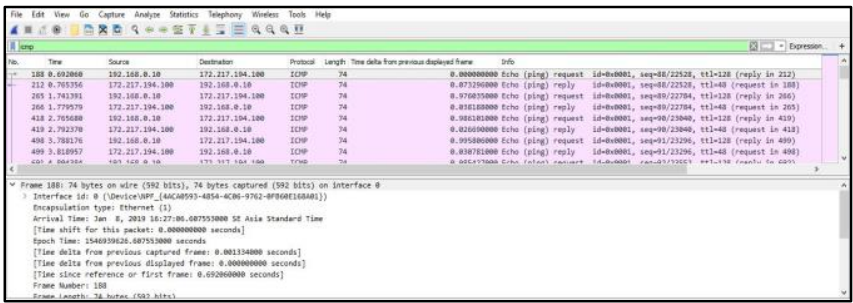

Fig 19. Delay testing

Packet loss testing is done to find out how many packets are lost on a network. Packet loss testing uses the ICMP package on Wireshark by pinging the site www.google.com from CMD. Package information captured by Wireshark, such as Google's IP Address, user's IP Address, source, destination can be seen in the picture below.

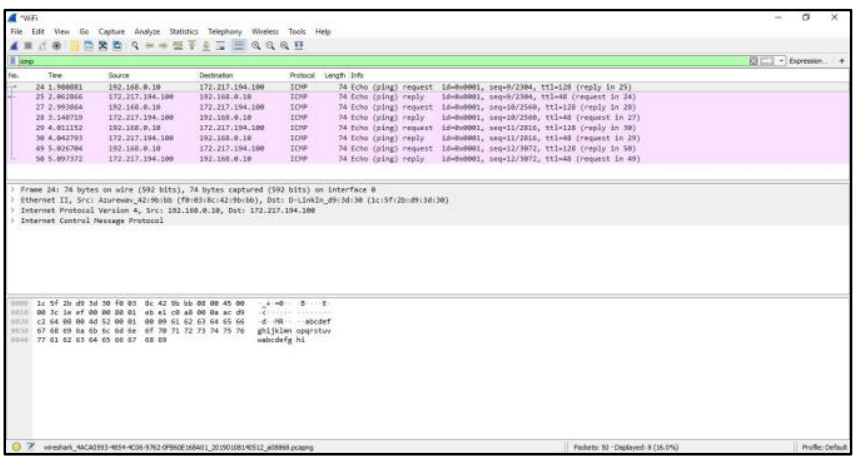

Fig 20. Packet loss testing

VIII. CONCLUSION

Based on the results of the Job Training (PKL) conducted at PT Aplikanusa Lintasarta, it can be concluded that in the implementation of the Local Area Network (LAN) network using the HAP 952 Mikrotik router successfully performed. As for some of the final results in implementing a LAN network, that is, users can connect to the internet either through a network cable (UTP RJ-P5) or using wireless (via the Microtic Hotspot).

This is proven through Command Prompt (CMD) and accessing www.google.com through a web browser. The other tests used in the Local Area Network (LAN) network that the authors made, namely the www.detik.com site were successfully blocked and the bandwidth was successfully limited according to user needs. This is evidenced by accessing sites that have previously been blocked via the Mikrotik HAP 952 router. Testing the user's bandwidth by performing a speed test on the speedtest site such as www.openspeedtest.com. QoS testing is done using Wireshark software and calculates throughput, delay, and packet loss on LAN networks.

\section{REFERENCES}

[1] Fitriastuti, F. \& Utomo, D. P., 2014. Implementasi Bandwidth Management dan Firewall System Menggunakan Mikrotik OS 2.9.27. JURNAL TEKNIK, 4(1), pp. 1-9.

[2] Hasanah, F. U. \& Mubarakah, N., 2014. Analisis Kinerja Routing Dinamis dengan teknik RIP (Routing Information Protocol) pada Topologi Ring dalam Jaringan LAN (Local Area Network) menggunakan Cisco Packet Tracer. SINGUDA ENSIKOM, 7(3), pp. 118-124.

[3] Husain, et al., 2018. Pengaturan Bandwidth Managament dan Time Limitation Berbasis User Manager Mikrotik. Jurnal Mantik Penusa, 2(2), pp. 22-28.

[4] Khasanah, S. N., 2016. Keamanan Jaringan dengan Packet Filtering Firewall (Studi Kasus: PT. Sukses Berkat Mandiri Jakarta). Jurnal 
Khatulistiwa Informatika, 4(2), pp. 182-192.

[5] Purwanto, E., 2015. Implementasi Jaringan Hotspot dengan Menggunakan Router Mikrotik Sebagai Penunjang Pembelajaran (Studi Kasus : SMK Sultan Agung Tirtomoyo Wonogiri). Jurnal INFORMA Politeknik Indonusa Surakarta, 1(2), pp. 20-27.

[6] Rahmawati, 2015. Konfigurasi Keamanan Jaringan Komputer Pada Router Dengan Metode ACL'S. Jurnal Teknik Komputer AMIK BSI, 1(2), pp. 152-158.

[7] Statista, 2018. Number of internet users worldwide from 2005 to 2018 (in millions). [Online]

Available at: https://www.statista.com/statistics/273018/number-ofinternet-users-worldwide/

[Accessed 20 March 2019].

[8] Sulaiman, K., 2016. Analisis Sistem Keamanan Jaringan Dengan Menggunakan Switch Port Security. Journal Of Computer Engineering, System And Science, 1(1), pp. 9-14.

[9] Wulandari, R., 2016. ANALISIS QoS (QUALITY OF SERVICE) PADA JARINGAN INTERNET (STUDI KASUS : UPT LOKA UJI TEKNIK PENAMBANGAN JAMPANG KULON - LIPI). Jurnal Teknik Informatika dan Sistem Informasi, 2(2), pp. 162-172. 